\title{
TRIFLUOROETHYLVINYL ETHER (FLUROXENE, FLUOROMAR IN OBSTETRICS
}

\author{
Elizabeth M. Martin, M.D., and Jerry N. Bosnak, M.D.*
}

Orstetrical anaEsthesia must consider the mother, the child, and the contracting uterus. Therefore, general anaesthesia for obstetrics requires a rapidly acting, non-irritating, potent agent capable of quickly achieving the desired depth of anaesthesia with a minimum of disturbance to the physiology of the mother br infant. This agent should cause no excess secretion, no nausea or vomiting, and should be rapidly eliminated. It must produce uterine relaxation if necessary, but leave the contractile power of the uterus unimpaired in light planes of anaesthesia. A high degree of analgesia would be appreciated. It must be compatible with all the commonly used medications and oxytocics ${ }^{1}$ and it should be nonexplosive.

Trifluoroethylvinyl ether (fluroxene, Fluoromar ${ }^{\circledR}$ ) appears to approach this ideal closely. This new inhalation anaesthetic agent is a volatile liquid stabilized with 0.01 per cent $n$-phenyl-1-naphthylamine. Its physical properties resemble those of diethyl ether, ${ }^{2}$ which makes it easy to use in all conventional gas anaesthesia apparatus. The liquid is flammable but it is not explosive in anaesthetic mixtures, especially when used with the circle filter. ${ }^{3}$ It is capable of producing safe, rapid, and profound anaesthesia with a minimum of irritation or nausea and vomiting. 4.5

Our clinical investigation commenced shortly after the early report of the clinical use of this agent by H. M. Slater. ${ }^{5}$ It proved to be very useful in outpatient anaesthesia and almost immediately suggested itself for use in obstetrics. Here it met with such overwhelming acceptance that the somewhat limited supply was held for obstetrical use. The cases discussed in this study were anaesthetized in Hudson, New York, and Wooster, Ohio. All of the anaesthetics were given by one of the authors (E.M.M.). The obstetric evaluation was made by the other (J.N.B.).

Fluoromar was used in several different vaporizers. The Heidbrink vaporizer No. 8 with string wick was found satisfactory, as was the ether drip cup or copper kettle provided with the Foregger machine. The usual rate of use has been four to five cases for each t-ounce bottle of Fluoromar.

Initially we used nitrous oxide with Fluoromar but found that it was more likely to cause tachypnoea, and in some patients even at 50-50 oxygen - nitrous oxide, duskiness was noted in the mother. We have been more pleased using Fluoromar with oxygen alone. Our Pharmacy has predicted that the per case cost to the obstetrical department will be similar to that of cyclopropane.

In discussing any new anaesthetic agent for obstetrics, it is in order to review briefly the various medications used by our group. Nearly all patients in labour received, upon request, meperidine $50 \mathrm{mg}$. and promethazine $25 \mathrm{mg}$. Nisentil ${ }^{\circledR}$ and Largon ${ }^{\circledR}$ are used occasionally. Analgesia is supplemented with trichlorethylene from the Duke inhaler. Patients who are admitted directly to the delivery

*Wooster Community Hospital, 1716 Beall Avenue, Wooster, Ohio, U.S.A. 
room may be given $25 \mathrm{mg}$. of promethazine intravenously. This drug has largely replaced both atropine and scopolamine in the delivery room.

Oxytocics vary with each operator's preference. Ergotrate ${ }^{\circledR}$ gr. 1/320 intravenously with Pitocin ${ }^{\circledR} 10$ units intramuscularly, or Ergotrate ${ }^{\circledR}$ gr, $1 / 320$ and Pitocin 10 units intramuscularly, is a favourite combination. If there is a Pitocin ${ }^{\circledR}$ drip running it is discontinued until after the placenta is delivered. It may be restarted and Ergotrate ${ }^{(\mathbb{B})}$ given as well.

We have been accustomed to using 3-6 mg. of tubocurarine chloride to relax the perineum in primiparae and well-repaired multiparae. With Fluoromar, onehalf the usual dose appears to be sufficient and in some patients relaxation has been adequate with Fluoromar alone.

It rapidly became apparent that Fluoromar was the anaesthetic of choice in persistent posterior presentations. The analgesia is far superior to that of trichlorethylene or nitrous oxide. The patients were able to follow instructions and could "bear down" much more -effectively because of the excellent analgesia. This usually resulted in spontaneous rotation. Fluoromar anaesthesia needed to be deepened but very little for episiotomy and spontaneous delivery or forceps extraction. Manual or forceps rotation of the non-rotating head was easily accomplished with deepening of the level of anaesthesia.

The patient seldom required an airway, but care must be exercised to have sufficient depth of anaesthesia before insertion. The pharyngeal reflex seems to be abolished at about the same stage as with the cyclopropane anaesthesia. There has been little nausea or vomiting. We have had only one patient retch on induction. This patient had an empty stomach but had been nervous during labour and had swallowed a good deal of air. Emergence nausea and vomiting was rare, even in those patients who had eaten shortly before delivery.

Fluoromar relaxes the uterus sufficiently for intrauterine manoeuvres such as version or breech extraction without affecting the foetus adversely. The agent is so rapidly eliminated that lightening the depth of anaesthesia as soon as the delivery is accomplished permits the placenta to separate within three minutes or less, with a minimum of bleeding despite long, hard labours and manipulation. This expecially recommends it to our obstetricians for those cases where block anaesthesia is a positive hazard.

A total of 155 obstetrical patients have had Fluoromar anaesthesia. Of these, 97 were in the first or Hudson series, and 58 have been in Wooster during the past year.

Of the infants in this total series, there have been four sets of twins. The second twin appeared in each case to be as active as his predecessor in spite of the somewhat lengthier anaesthesia. There were 21 breech presentations, of which 19 were frank breeches and 2 were single footling. There were 86 persistent posterior, of which 23 were rotated either manually or with forceps, and 63 were spontaneous rotations at the outlet. There were, also, one arm and shoulder presentation, one hydrocephalic, and one stillbirth known before labour. Thus, 41 cases were quite normal and 114 were somewhat complicated. One of the patients with a persistent posterior had a concealed eclampsia. The oedema and rising blood pressure were contained by drugs until the delivery. Then, because the patient showed only a 
trace of albumin, this medical regime was abandoned after the birth of the infant. There was no elevation of this patient's blood pressure beyond that normally occurring in labour. The first post-partum day this patient convulsed and her blood pressure was then quite abnormally elevated. We checked the labour record and at no time had it been other than normal. We did not believe that the Fluoromar was a factor in this case, and the patient made an uneventful recovery. There have been three similar cases on the obstetrical service this past year. All had been on diuretics and rauwolfia compounds. A little more than normal weight gain and a slight trace of albumin were the only signs of impending trouble, yet all three had convulsive seizures 6 or 8 hours post-partum. Only one had Fluoromar, one had a spinal, and one cyclopropane anaesthesia.

The following case reports give some idea of the wide range of usefulness of Fluoromar ${ }^{\circledR}$ in obstetrics.

Case 1 (para 6 , gravida 7 , age 40 ). This patient came to the hospital fully dilated with intact membranes. The position was diagnosed as a breech by the obstetrical nurse, and the physician was notified. As the anaesthetist arrived on the floor the membranes ruptured and a hand presented. The physician arrived almost immediately and called for a consultation with the Chief of Obstetrics (J.N.B.). This patient had had no premedication. Atropine gr. $1 / 150$ was given intravenously, and an intravenous infusion of 1,000 c.c. of glucose and water was started as a precaution. It was felt that if labour could be quickly stopped before the shoulder was impacted the consultant would have time upon arrival to evaluate the situation and decide upon action without compromising mother or child. It was felt that Fluromar would provide the necessary time required. The patient went to sleep rapidly and smoothly and in six minutes uterine contractions stopped. Six minutes after this the consultant arrived. After a thorough evaluation of the situation, because of the full dilatation and relaxed uterus, a version and extraction was quickly and easily performed. The infant breathed within 30 seconds and cried at one minute. In the meantime the anaesthesia was lightened, and the placenta was expressed in four minutes. Intravenous Ergotrate ${ }^{\circledR}$ gr. 1/320 and intramuscular Pitocin ${ }^{\otimes} 10$ units were given and the blood loss was felt to be less than normal. The episiotony was repaired and the mother was sufficiently awake upon removal to the delivery cart that she was allowed to carry the baby with her to the room as she requested.

Case $\mathscr{2}$ (para 1, gravida 2, age 32 ). This patient had previously delivered an 8-pound child after an 8-hour labour. She had been in indifferent labour for about 20 hours, making slow progress. Then her labour pains became more regular and forceful, but cervical dilatation seemed to stop at about $6 \mathrm{~cm}$. An obstructed labour was suspected. The X-ray showed a huge hydrocephalus. Even with the $\mathrm{X}$-ray evidence it was impossible to diagnose this by palpation of the abdomen because the skull was so extremely soft. The patient had had meperidine $50 \mathrm{mg}$. and promethazine $50 \mathrm{mg}$. about one hour previously. This had, if any'thing, speeded up and fortified the contractions. It was felt that labour should be stopped if possible and yet it was desired to be able to restart it and to finish dilating the cervix when decompression should have made the head small enough to deliver. 
Fluoromar accomplished this. The patient had three contractions in the next fifteen minutes and none at all in the next half hour while the cerebrospinal fluid was being removed by spinal needle from the baby's head. The anaesthesia was then lightened and the labour progressed to full dilatation, the patient pushed the head to the introitus when episiotomy was performed, and low forceps extraction was done under analgesia. The patient was awake at the end of the episiotomy repair, after nearly two hours of anaesthesia and analgesia. She had no nausea or vomiting, and suffered no ill-effects.

Case 3 (para 0 , gravida 1 , age 23). This was a frank breech which was not recognized until after a saddle block had been given by the obstetrician. He had felt that he was dealing with a persistent posterior in a patient with full dilatation and had started some Pitocin ${ }^{\circledR} 10$ units in 500 c.c. of normal saline, at 8-10 drops per minute. The ruling of the department calls for consultation in the delivery of a primiparous breech. As soon as a vaginal examination revealed the situation, the Pitocin ${ }^{\circledR}$ was stopped and the Chief of Obstetrics was called. The breech was snug and spinal anaesthesia plus Pitocin ${ }^{\circledR}$ had brought the uterus down too tightly to manipulate the legs. The patient was given Fluoromar, obtaining uterine relaxation,within five minutes in spite of some induction difficulty. This was the first and only time we had any retching and vomiting of air. The breech was quickly decomposed and delivered as a double footling with a small midline episiotomy. Relaxation of the perineum was enhanced by $\pm \frac{1}{2} \mathrm{mg}$. of tubocurarine choloride. The infant breathed in 10 seconds and cried in 30 seconds. The mother was awake on completion of the episiotomy repair, but she was still nauseated and remained so for half an hour until relieved by $\tilde{a} \mathrm{mg}$. of Compazine ${ }^{\circledR}$.

J. N. Bosnak, Chief of Obstetrics, feels this is the most manoeuvrable obstetrical anaesthetic agent to come to his attention. The other obstetricians have been universally pleased with its use for their more complicated cases.

Another very interesting sidelight has been shed by the patients. A number of the grand multiparae have said that this is the most agreeable general anaesthetic of their many and varied experiences. Several of the women, one a doctor's wife, have mentioned that they have had the most ecstatic dreams. These can't be recalled in detail, but are reported as an intensely pleasant experience. Emergence delirium has been rare, even in heavily sedated patients. The babies have appeared to suffer ill-effects only fron excessive premedication. The babies depressed by meperidine responded promptly to $0.5 \mathrm{mg}$. of levallorphan (Lorfan ${ }^{\circledR}$ ).

\section{SUMMARY}

The use of trifluoroethylvinyl ether (fluroxene, Fluoromar ${ }^{\circledR}$ ) for obstetrical anaesthesia and analgesia has been described. This agent is potent, non-toxic, and acceptable to the patients. It offers specific advantages over other agents in certain obstetrical complications.

This is a very manoeuvrable agent the capabilities of which will best be fully? explored by cautious use in the hands of experienced anaesthesiologists.

We feel that Fluoromar ${ }^{\circledR}$ is a distinct addition to the armamentarium of those who do obstetrical anaesthesia. 


\section{RÉSUMÉ}

En obstétrique, il faut, pour faire l'anesthésie générale, un agent puissant, nonirritant, à action rapide, permettant d'atteindre le niveau d'anesthésie désiré en occasionnant un minimum de perturbation à la physiologie de la mère ou de l'enfant. Cet agent doit pouvoir procurer une atonie utérine si nécessaire, mais laisser à l'utérus son pouvoir de contraction intact sous anesthésie légère. Il faut que cet agent soit compatible avec tous les médicaments d'usage courant ainsi que les oxytociques et qu'il ne soit pas explosif.

L'éther trifluoroéthylvinylique (fluoroxene, Fluoromar ${ }^{\circledR}$ ) semble se rapprocher de près de cet idéal. C'est un liquide volatil qui peut être employé dans tous les appareils à gaz anaesthésiques conventionnels. C'est inflammable mais ce n'est pas explosif en mélanges anesthésiques. Les auteurs nous font part de leur expérience avec cet agent dans 155 cas d'obstétrique.

Ils ont prémédiqué ces malades avec de la méperidine $50 \mathrm{mg}$. et de la prométhazine $25 \mathrm{mg}$. et, à l'occasion, du Nisentil ${ }^{\circledR}$ et du Largon ${ }^{\circledR}$. Ils ont employé aussi bien de l'ergot que de la pitocine en même temps que le Fluoromar et ils ont noté aucun incident. Ils ont également employé de la tubocurarine pour relâcher le périnée chez les primipares et la moitié de la dose a suffi.

L'éther trifluoroéthylvinylique a procuré des niveaux d'analgésie adéquats rapidement et, avec cet agent, ils ont obtenu un relâchement utérin suffisant pour faire des manipulations intra-utérines. En rendant l'anesthésie plus légère, les contractions utérines sont apparues de nouveau rapidement.

Cet agent, chez les bébés, n'a pas provoqué de dépression notable. Les nausées et les vomissements ont été très rares.

C'est un agent très souple qui est une acquisition de valeur pour l'armamentırium de ceux qui s'occupent d'anesthésie obstétricale.

\section{ACKNOWLEDGMENTS}

The authors wish to express their grateful appreciation to Mrs. Dorothy Boling, registered pharmacist, and the staff of the Record Room of Wooster Community Hospital for their assistance in correlating the material for this paper.

\section{REFERENCES}

1. Cavallaro, R. J. \& Dornette, WM. H. L. Fluoromar Anesthesia in Obstetrics. Obstetrics \& Gynecology 17: $447^{\text {(2) }}(1961)$.

2. Krantz, J. C., Jr.; Cark, J.; Lu, G.; \& Bell, F. K. Anesthesia. Xl. The Anesthetic Action of Trifluoroethyl Vinyl Ether. J. Pharmacol. \& Exper. Therap. 108: 188 (1953).

3. Miller, G. L. \& Dornette, W M. H. L. Flammability Studies of Fluoromar-Oxygen Mixtures used in Anesthesia. Anesth. \& Analg. 40: 232 (1961).

4 Gainza, E.; Heaton, E.; Willcox, M ; \& Virtue, R. Physiological Measurenents during Anaesthesia with Fluoromar. Brit. J. Anaesth. 28: 411 (1956).

5. Slatrr, H. M. The Use of Trifluoroethylvingl Ether (Fluoromar) in Anaesthesia for Dentistry. Canad Anesth. Soc. J. 4:5 (1957). 